\title{
Generation of multistate release- recapture models using a graphic user interface (GUI)
}

\author{
Adam C. Pope ${ }^{1,2 \dagger}$, John R. Skalski ${ }^{3^{*}+}$, Trisha Lockhart ${ }^{3 \dagger}$ and Rebecca A. Buchanan ${ }^{3 \dagger}$
}

\begin{abstract}
Background: Multistate release-recapture models are used to study the movements and survival of animals when multiple migration pathways exist. Model complexity increases exponentially as the number of possible migration pathways increases.

Results: Program Branch was developed as freeware to allow users to construct multistate release-recapture models based on a schematic of the study design built with a graphic user interface (GUI). The GUI can be used not only to develop the underlying statistical likelihood models but to direct the estimation of summary performance parameters. Program Branch is illustrated using the spawning behavior of shortnose suckers (Chasmistes brevirostris) in northern California, juvenile Chinook salmon (Oncorhynchus tshawytscha) outmigration through the Sacramento-San Joaquin Delta of California, and adult steelhead (Oncorhynchus mykiss) migration in the Columbia/Snake River Basin in the Pacific Northwest.

Conclusions: This software, available online at http://www.cbr.washington.edu/analysis/apps/branch, makes the analysis of complex multistate models easier and allows investigators to review study designs to ensure important model parameters are estimable.
\end{abstract}

Keywords: Acoustic tags, Chinook salmon, Digraph theory, Multistate model, PIT tags, Release-recapture, Shortnose sucker, Steelhead, Tagging studies

\section{Background}

Characterizing the survival and movement of animals in the wild is the cornerstone to many demographic analyses. Release-recapture studies have been used to estimate the survival probabilities of wild populations for decades [1]. Brownie et al. [2] developed a method to analyze the release-recovery data from bird banding studies of waterfowl populations. In these early singlestate models, all animals have the same probability of transition from event $i$ to event $i+1$ regardless of prior disposition. However, animal survival may be a factor of

\footnotetext{
*Correspondence: skalski@uw.edu

${ }^{\dagger}$ Adam C. Pope, John R. Skalski, Trisha Lockhart and Rebecca A. Buchanan contributed equally to this work

${ }^{3}$ School of Aquatic and Fishery Sciences, University of Washington, 1325

Fourth Avenue, Suite 1515, Seattle, WA 98101-2540, USA

Full list of author information is available at the end of the article
}

an individual's choice of migration pathway or maturation state. To this end, multistate release-recapture models have been developed, which allow survival and other parameters to vary between transition states.

Originally, release-recapture models were developed envisioning the physical recapture of the tagged animals to obtain survival information. However, the advent of PIT tags [3, 4], radio tags [5-7], acoustic tags [8, 9], and satellite tags $[10,11]$ has changed the nature of releaserecapture studies. Animals need no longer be physically recaptured to obtain detection histories within complex networks of detection sites. The result is greater resolution of animal movements and survival without the concern that recapture and rehandling may alter animal behavior and violate model assumptions.

Avian biologists were among the first to use multistate models. Hestbeck et al. [12] analyzed the movement 
between and the fidelity to wintering areas of Canada geese (Branta canadensis) using a multistate model. Natal dispersal, breeding dispersal, and age-specific recruitment rates of roseate tern (Sterna dougallii) were estimated using multistate models of Lebreton et al. [13]. Doherty et al. [14] used a multistate model to estimate age-specific breeding and survival probabilities of redtailed tropicbirds (Phaethon rubricauda).

Multistate models have also played an important role in the study of mammalian demographics. Releaserecapture methodology was used by Aars and Ims [15] to explore the effects of habitat corridors on populations of root voles (Microtus oeconomus). More recently, a multistate model was used by Pyne et al. [16] to estimate survival rates stratified by age, sex, and breeding status for a reintroduced population of plains bison (Bison bison).

Multistate models have also been useful in characterizing the sometimes complex migration behavior of fish. Buchanan and Skalski [17] examined adult Chinook salmon (Oncorhynchus tshawytscha) upstream migration through the hydroelectric system in the lower Columbia and Snake rivers of Washington and Oregon using multistate models. Buchanan et al. [18] developed multistate models to estimate the success rate of in-river and transported juvenile salmonids in the Columbia Basin. Perry et al. [19] and Buchanan et al. [20] have used multistate models to characterize survival through the complex migration pathways in the Sacramento-San Joaquin River Delta of California for juvenile Chinook salmon and steelhead (Oncorhynchus mykiss). Buchanan et al. [21] also estimated in-stream survival of juvenile steelhead that migrate through tributaries between 1 and 6 years of age using multistate models.

There are computer programs available to help investigators analyze multistate release-recapture studies. Both M-SURGE [22] and MARK [23, 24] allow specifications of model structures, parameter restrictions, number of recapture opportunities, and number of model states through typed input. While these approaches allow for a great deal of flexibility in model specification, they do not easily accommodate certain Arnason-Schwarz [25] multistate models where, as in river systems, state transitions are highly constrained. In migratory fish models, movement tends to be more unidirectional with fewer opportunities for fish to backtrack or move out of the system. It is easier to specify these simpler types of models graphically using a graphical user interface (GUI) and let the software automatically create the likelihood model used in parameter estimation. Automation of model creation may also be necessary as increasingly complex systems are investigated [26].

The purpose of this paper is to describe the use of digraph theory to translate schematics of multistate processes into maximum likelihood models. The approach will be illustrated using the software Program Branch (http://www.cbr.washington.edu/analysis/apps/branch) and the creation of multistate models of migration and survival of adult shortnose suckers (Chasmistes brevirostris) in the Clear Lake Reservoir in northern California, juvenile Chinook salmon in the San Joaquin Delta of California, and adult steelhead migrating to the Walla Walla River in Washington State. We hope this paper will help investigators to better design and analyze multistate models, and prompt further development of GUI-driven models in the field.

\section{Program development}

The structural features of multistate models suggest a generalized, automated approach to their analysis is possible. One such feature is the association of a single transition parameter with each possible path from one recapture opportunity and/or model state to another. Another feature is the directional nature of these models, as animals must move through either time or space. By linking the study design schematic to a set of rules, it is possible to write a statistical likelihood model for the multistate process. The development of this capability requires a number of analytical and computational steps, as described below.

The first step is a way for the user to draw a schematic of the study design. A GUI allowing point-and-click and mouse drag operations can achieve this task. The user can select among a series of icons to place on a canvas and can drag from one placed icon to another to indicate adjacency and direction. Second, the software must interpret the types of icons and their adjacency relationships into a meaningful quantitative framework. Once the diagram has been interpreted, the third step is to characterize and store each possible path a tagged animal can take through the study as well as the model parameters associated with survival, movement, and detection. The fourth step is to write a likelihood equation using the parameters and spatial and temporal relationships specified in the diagram. Fifth, the program must decide what model parameters are estimable, and which parameters are not separable and must be combined. Sixth, the program must be able to determine whether any additional re-parameterization is necessary, given the data from the study, which is input by the user. Seventh is numerical optimization of the likelihood model to estimate the parameters. Finally, after estimation of the user-specified model parameters, the program should be capable of summarizing survival or movement processes across the system being modeled.

\section{Algorithm development}

The purpose of Program Branch is to translate a schematic of a multistate release-recapture study into a maximum 
likelihood model [27: 38-81] in order to extract survival and movement probabilities of tagged animals. Multiple steps are required to produce an algorithm that is userfriendly, flexible, and capable of generating meaningful results. In general, multistate models are written as a function of detection/capture probabilities and transition parameters that describe the joint probability of an animal making a migration choice and surviving. Afterward, these transition probabilities must be recombined in meaningful ways to estimate survival and route selection. Standard errors need to be calculated for both directly estimated and derived parameter values.

Program Branch begins with a graphical user interface (GUI) that allows point, click, and drag operations using a series of icons placed on a canvas. The GUI allows users to construct schematics of the multistate releaserecapture model by indicating paths of movement and detection locations. The user constructs the schematic sequentially, one step at a time, and can erase steps made in error. Subsequently, the software interprets the icons and their adjacency relationships into a meaningful format for machine processing. Once the diagram has been interpreted, each possible path a tagged animal can take through the study is completely enumerated and stored, as well as the model parameters associated with survival, movement, and detection. Using the enumerated pathways, the software codes a product-multinomial likelihood equation using the parameters and spatial and temporal relationships specified in the diagram. The program also identifies which model parameters are estimable as specified, and which parameters are not separable and must be combined. This distinction is performed both when the model is first created by the user, and again after the user has input the data, because sparse data may require additional model re-parameterization. Numerical optimization is then used to calculate the maximum likelihood estimates for the model parameters and associated variance-covariance matrix. Finally, after estimation of the user-specified model parameters, the program has the capability of summarizing survival or movement processes across the entire system being modeled.

The diagram drawn of the multistate model is translated into information used to code the maximum likelihood model based on digraph theory [28]. A digraph or directed graph consists of a set of vertices and a set of arcs. In release-recapture studies, the vertices are survival, captures, and redirection events ("forks" or "branches") depicted in the study schematic. Arcs are the sequential transitions from one vertex to another. An adjacency matrix is a useful way of conveying the model structure.

In the adjacency matrix, a value of 1 denotes two adjacent vertices or events in the direction of the movement
(Fig. 1). The order of the rows and columns is unimportant. In multistate models, the names of the vertices are the types of model parameters that represent survival $(S)$, branching $(\gamma)$, and detection $(P)$ events. The pathways through the multistate model can then be traced through the set of arcs in the matrix (Fig. 1). The illustrated branching model consists of a release of tagged animals $(R), 9$ survival parameters $(S), 2$ branching parameters $\left(\gamma_{1}, \gamma_{2}\right)$, and 7 detection probabilities (Fig. 1). The corresponding $19 \times 19$ adjacency matrix includes information on which events are sequential and the three various pathways through the study. Note the column $R$ in the matrix does not have an entry of 1 . This is because $R$ is the release parameter, and there are no arcs leading into the release point, only leading out.

One approach is to construct a multinomial likelihood based on all possible migration pathways and recapture opportunities. This process creates a detection history for each fish, which can be written as an $n$-digit binary number, where $n$ is the number of recapture opportunities in the model, and each digit $d_{i}(i=1, \ldots, n)$ equals 1 if an animal is recaptured at detection array $i$ and 0 otherwise. A multinomial likelihood equation is then created based on all possible histories.

Alternatively, to develop an algorithm to write a likelihood equation from the adjacency matrix, it is simpler to break the detection histories into single steps. The product of these conditional likelihoods is equivalent to the unconditional multinomial model based on full capture histories.

Writing a conditional product-multinomial likelihood equation can be accomplished by following a simple set of rules. The adjacency matrix provides a list of parameters along each possible path through the model. The probability of detection at site $j$ given previous detection at site $i$ (where $j>i$ and $i=0$ is the release point) is the sum of the probabilities for all possible paths from site $i$ to site $j$. Each of these sub-paths is essentially atomic; that is, the probability of reaching $j$ from $i$ via each sub-path can be expressed simply as the product of the parameters along the sub-path, with $(1-P)$ substituted for each detection parameter $P$ to indicate non-detection at intermediate sites, and $(1-\gamma)$ substituted for $\gamma$ to indicate selection of the alternate branch at a fork. The total probability of detection at $j$, given detection at $i$, is the sum of these sub-path products. The conditional multinomial likelihood function is then based on all possible next sites, given detection at site $i$. The joint likelihood is the product over all sites $i$.

Consider a simple single-state model with an initial release and three subsequent recapture opportunities. Given an animal can be recaptured or not at each of the three opportunities, there are $2^{3}=8$ unique possible 


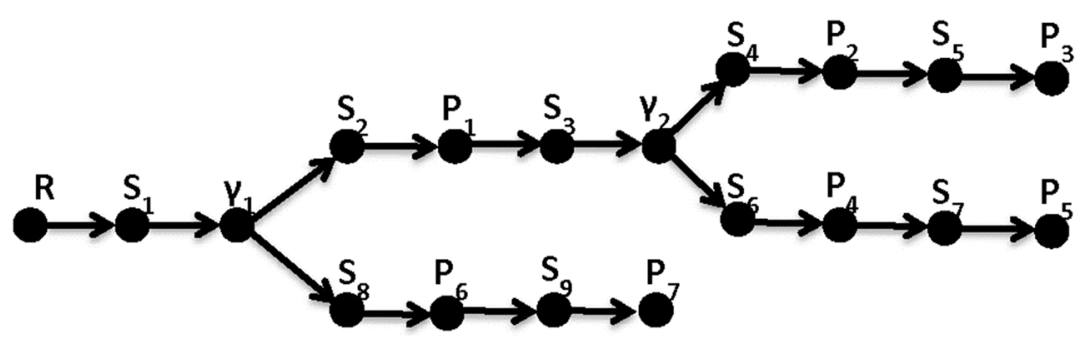

\begin{tabular}{|c|c|c|c|c|c|c|c|c|c|c|c|c|c|c|c|c|c|c|c|}
\hline & $\mathbf{R}$ & $\mathrm{S}_{1}$ & $V_{1}$ & $\mathrm{~S}_{2}$ & $P_{1}$ & $\mathrm{~S}_{3}$ & $V_{2}$ & $\mathrm{~S}_{4}$ & $P_{2}$ & $S_{5}$ & $P_{3}$ & $S_{6}$ & $\mathbf{P}_{4}$ & $S_{7}$ & $P_{5}$ & $\mathrm{~S}_{8}$ & $P_{6}$ & $S_{9}$ & $P_{7}$ \\
\hline $\mathrm{R}$ & & 1 & & & & & & & & & & & & & & & & & \\
\hline $\mathrm{S}_{1}$ & & & 1 & & & & & & & & & & & & & & & & \\
\hline$\gamma_{1}$ & & & & 1 & & & & & & & & & & & & 1 & & & \\
\hline $\mathrm{S}_{2}$ & & & & & 1 & & & & & & & & & & & & & & \\
\hline$P_{1}$ & & & & & & 1 & & & & & & & & & & & & & \\
\hline $\mathrm{S}_{3}$ & & & & & & & 1 & & & & & & & & & & & & \\
\hline$\gamma_{2}$ & & & & & & & & 1 & & & & 1 & & & & & & & \\
\hline $\mathrm{S}_{4}$ & & & & & & & & & 1 & & & & & & & & & & \\
\hline$P_{2}$ & & & & & & & & & & 1 & & & & & & & & & \\
\hline $\mathrm{S}_{5}$ & & & & & & & & & & & 1 & & & & & & & & \\
\hline$P_{3}$ & & & & & & & & & & & & & & & & & & & \\
\hline $\mathrm{S}_{6}$ & & & & & & & & & & & & & 1 & & & & & & \\
\hline $\mathrm{P}_{4}$ & & & & & & & & & & & & & & 1 & & & & & \\
\hline $\mathrm{S}_{7}$ & & & & & & & & & & & & & & & 1 & & & & \\
\hline$P_{5}$ & & & & & & & & & & & & & & & & & & & \\
\hline $\mathrm{S}_{8}$ & & & & & & & & & & & & & & & & & 1 & & \\
\hline $\mathrm{P}_{6}$ & & & & & & & & & & & & & & & & & & 1 & \\
\hline $\mathrm{S}_{9}$ & & & & & & & & & & & & & & & & & & & 1 \\
\hline $\mathrm{P}_{7}$ & & & & & & & & & & & & & & & & & & & \\
\hline
\end{tabular}

Fig. 1 Digraph representation of a multistate model. Digraph representation of a multistate model with associated table that depicts the adjacency matrix representation of the digraph. $R$ denotes release location of tagged animals; $S$ survival; $\gamma$ choice of movement direction; and $P$ detection probability

capture histories. Letting a 1 denote recapture and a 0 , not recaptured, then $n_{101}$ denotes the number of animals released $(R)$ with subsequent capture history 101. A multinomial distribution with eight possible capture histories can then be used to model the three-period releaserecapture investigation where and where $S_{i}$ and $P_{i}$ denote survival and detection probabilities in periods $i=1,2$ and $\lambda$ is the joint probability of surviving and being detected in the last (i.e., third) period.

Alternatively, a conditional product-multinomial approach can be used to equivalently describe a

$$
\begin{aligned}
L_{0}= & \left(\begin{array}{l}
R \\
\vec{n}
\end{array}\right)\left(S_{1} P_{1} S_{2} P_{2} \lambda\right)^{n_{111}}\left(S_{1}\left(1-P_{1}\right) S_{2} P_{2} \lambda\right)^{n_{011}} \\
& \times\left(S_{1} P_{1} S_{2}\left(1-P_{2}\right) \lambda\right)^{n_{110}}\left(S_{1}\left(1-P_{1}\right) S_{2}\left(1-P_{2}\right) \lambda\right)^{n_{001}} \\
& \times\left(S_{1} P_{1} S_{2} P_{2}(1-\lambda)\right)^{n_{101}}\left(S_{1}\left(1-P_{1}\right) S_{2} P_{2}(1-\lambda)\right)^{n_{010}} \\
& \times\left(S_{1} P_{1}\left(\left(1-S_{2}\right)+S_{2}\left(1-P_{2}\right)(1-\lambda)\right)\right)^{n_{100}} \\
& \times\left(\left(1-S_{1}\right)+S_{1}\left(1-P_{1}\right)\left(\left(1-S_{2}\right)+S_{2}\left(1-P_{2}\right)(1-\lambda)\right)\right)^{n_{000}}
\end{aligned}
$$


three-period, single release-recapture study. Upon release, an animal could next be seen for the first time in periods 1,2 , or 3 or not seen ever again. These capture events can be modeled as

$$
\begin{aligned}
L_{1}= & \left(\begin{array}{l}
R \\
\vec{n}
\end{array}\right)\left(S_{1} P_{1}\right)^{n_{1}}\left(S_{1}\left(1-P_{1}\right) S_{2} P_{2}\right)^{n_{01}} \\
& \times\left(S_{1}\left(1-P_{1}\right) S_{2}\left(1-P_{2}\right) \lambda\right)^{n_{001}} \\
& \times\left(\left(1-S_{1}\right)+S_{1}\left(1-P_{1}\right)\left(\left(1-S_{2}\right)+S_{2}\left(1-P_{2}\right)(1-\lambda)\right)\right)^{n_{000}} .
\end{aligned}
$$

For the $n_{1}$ animals detected in period 1 , they could next be detected in periods 2 or 3 , or not seen again. These three events can be modeled as

$$
\begin{aligned}
L_{2}= & \left(\begin{array}{c}
n_{1} \\
\vec{n}
\end{array}\right)\left(S_{2} P_{2}\right)^{n_{1 \mid 1}}\left(S_{2}\left(1-P_{2}\right) \lambda\right)^{n_{01 \mid 1}} \\
& \times\left(\left(1-S_{2}\right)+S_{2}\left(1-P_{2}\right)(1-\lambda)\right)^{n_{00 \mid 1}} .
\end{aligned}
$$

The notation $n_{00 \mid 1}$ denotes the number of animals with capture history 00 in periods 2 and 3 , given $(\mid)$ detected in period 1 . Other capture history counts are defined analogously.

For the $n_{01}$ animals detected in period 2 for the first time and the $n_{11 \mid 1}$ animals detected in period 2 after being detected initially in period 1 , they could be $(\lambda)$ or could not be $(1-\lambda)$ detected in period 3 , and modeled as

$$
L_{3}=\left(\begin{array}{c}
n_{01}+n_{01 \mid 1} \\
\vec{n}
\end{array}\right) \lambda^{n_{1 \mid \cdot 1}}(1-\lambda)^{n_{0 \mid \cdot 1}} .
$$

The product $L_{1} \times L_{2} \times L_{3}$ is equivalent to the unconditional likelihood $L_{0}$. In a small example like this one, the benefits of using the conditional product-multinomial modeling approach over the unconditional multinomial approach $\left(L_{0}\right)$ is minimal. However, with complex multistate models, the advantage becomes rapidly apparent. Generally, there will be fewer cell probabilities to compute, and it is easier to identify and account for all possible detection histories using the conditional likelihood approach.

In release-recapture studies in general and multistate models in particular, as depicted in Fig. 1 and its associated adjacency matrix, not all parameters are estimable. In the last reach of any branch, the probability of detection $(P)$ is not separable from the probability of survival $(S)$. In reaches with a fork, the probability of survival $(S)$ is not separable from the probability of an animal selecting a direction of movement $(\gamma)$ (or lack of movement). The computational algorithm must therefore reparameterize the multistate model parameters based on estimability before values can be calculated. The types of parameters estimated directly by Program Branch are the joint probability of route selection and survival ("transition" probability, $\phi=\gamma S$ ), the probability of detection $(p)$, and the joint probability of route selection, survival through the final reach, and detection at the final site $(\lambda=\phi P)$. It is also possible that additional model re-parameterizations may be necessary based on features of the data. Sparse data may require elimination or the combining of parameters for the model to be estimable.

\section{System-level parameter estimation}

Given the level of generality available in the design of multistate release-recapture models, it is difficult for an algorithm to predict what overall metrics will be of interest to investigators. In general, the parameters directly estimated by the models are the joint probabilities of an animal surviving and moving (or not moving) in a particular direction and through particular reaches or time periods. For example, for the two branches $\mathrm{A}$ and $\mathrm{B}$ possible at a fork (Fig. 2a), the sum of the probabilities of movement is equivalent to

$$
\phi_{\mathrm{A}}+\phi_{\mathrm{B}}=S_{\mathrm{A}}(\gamma)+S_{\mathrm{B}}(1-\gamma)
$$

where $S_{\mathrm{A}}=$ survival in the reach in branch A following the fork, $S_{\mathrm{B}}=$ survival in the reach in branch B following the fork, $\gamma=$ probability of animal taking branch $\mathrm{A}$ at the fork, and $1-\gamma=$ probability of animal taking branch B at the fork.

Equation (1) is seen to be the weighted survival of an animal taking either fork or, equivalently, the unconditional survival through that fork in migration. Program Branch will automatically calculate estimates of these forms of unconditional survival through the overall multistate system or through user-specified forks in the system, using the GUI to identify the beginning and end of such branched systems. The delta method [29: 7-9] is used to calculate the variance associated with these summary statistics. Program Branch internally checks for the validity of the requested summary survival statistics. Warnings of invalid summary statistics are signaled if GUI requests do not represent unconditional survival parameters. Warnings can be overridden at a user's request.

\section{Data formatting}

For each uniquely tagged animal, an identifier (ID) must be specified, along with the time (i.e., period) and location for each detection event. Program Branch converts this information into summary counts associated with the conditional multinomial likelihoods used to construct the joint likelihood model from the GUI representation of the multistate model. These summary counts can be examined for quality assurance/quality control (QA/QC) purposes, and are used in fitting the model. 


\section{a}

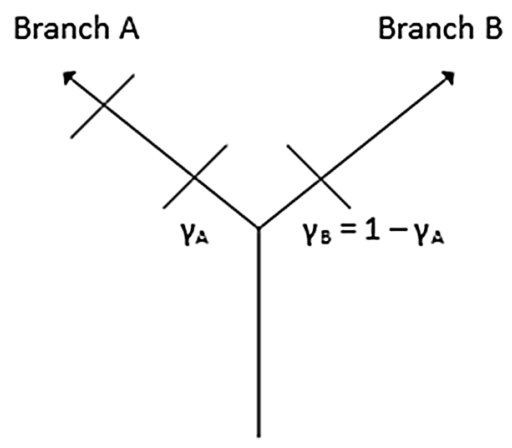

b

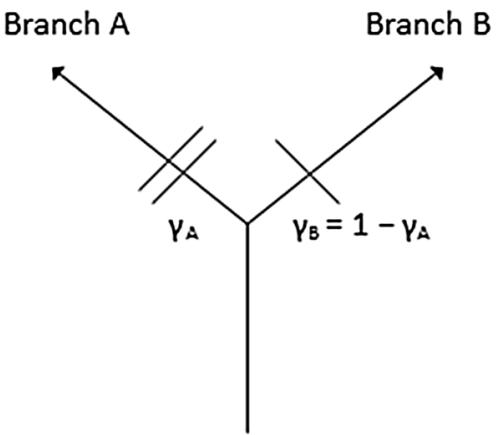

Fig. 2 Minimal receiver layouts. Minimal receiver layouts to estimate route selection probabilities $\gamma_{A}$ and $\gamma_{B}\left(\gamma_{A}+\gamma_{B}=1\right)$ using a two single receiver lines or $\mathbf{b}$ a dual-line receiver array. $\gamma$ denotes probability of moving in a particular direction

\section{Receiver placement for branching models}

Multistate models in general and Program Branch in particular estimate the joint probability of route selection and survival through that route (i.e., the "transition" probability). Route selection probabilities may be segregated from survival probabilities in fisheries investigations, but this requires particular care to be taken in designing the multistate release-recapture study. Fish migrating through a branching river tributary system or delta illustrate a type of release-recapture study wherein such parameter segregation is frequently performed. In such a study, recapture of tagged fish occurs via detection by receivers which can be placed at fixed locations in the river. Two assumptions must be made to estimate route selection probabilities, the validity of which depends on receiver placement. First, it is assumed that survival from the branching point to the first receiver line is the same for both branches (i.e., independent of route). Second is the assumption that detections on separate receiver lines are independent events.

If the first assumption (common survival) is violated, then the route selection estimate $\hat{\gamma}_{\mathrm{A}}$ (and its complement, $\hat{\gamma}_{\mathrm{B}}=1-\hat{\gamma}_{\mathrm{A}}$ ) will be biased based on the relative survival between the junction and receivers in the two legs. As an extreme example, consider the case in which the two routes are selected with equal probabilities $\left(\gamma_{\mathrm{A}}=\gamma_{\mathrm{B}}=1 / 2\right)$ but survival in route $\mathrm{B}$ to the receiver line is 0 , while survival in route $A$ is $>0$. The estimate of $\gamma_{A}$ will be $\hat{\gamma}_{\mathrm{A}}=1$, because all fish were detected only in route $\mathrm{A}$, even though equal numbers of fish actually entered the two routes. Because the assumption of common survival in the two routes generally cannot be made if any considerable distance to travel is required, it is safest to place the receivers in the branches as close to the branching point as possible without either overlap of the detection ranges or inclusion of the region before (upstream of) the branching point in the detection range.

The sites selected for detection locations/receivers dictate what parameters are estimable, especially in a system that branches into multiple migration pathways (states). If estimates of the route selection probabilities are desired in a spatial branching system, then receivers must be sited both to detect individuals that select each route and to estimate the detection probabilities in each route. For example, in order to estimate the route selection probability $\gamma_{\mathrm{A}}$, a minimum of three receiver lines are required: at least two in one route, and at least one in the other route (Fig. 2a). The two lines in the first route (either A or B) provide a detection probability estimate for the first line in that route, which when combined with detections in the second route, also provides a detection probability estimate for the second route. The two receiver lines in a given branch can be conceived of either as separate single arrays (Fig. 2a) or as a single dual-line array (Fig. 2b). Modeling them as separate single arrays allows for mortality between the lines, whereas modeling them as a dual array depends on the assumption that no fish die between passage of the two lines. However, accidents and equipment failures happen, so it is safer to place at least two lines in both routes.

An alternative layout that is sometimes attractive places a receiver line just before the branching point, and two or more receiver lines in one branch after the branching point (e.g., Fig. 3). The receivers after the branching point indicate the proportion of fish passing the first line that took that route, and also provide the data structure to estimate the detection probability of both the upstream receiver $\left(P_{1}\right)$ and the line after the junction $\left(P_{2}\right)$. No receivers are located in the second branch. This layout requires the assumption of perfect survival (100\%) through the region of the branch point (i.e., between the upstream and downstream receivers, including through a comparable region of the unmonitored route). If survival $<1$ through this region, then $\gamma$ will be underestimated for the route with the receivers, and overestimated for the route without the receivers. 


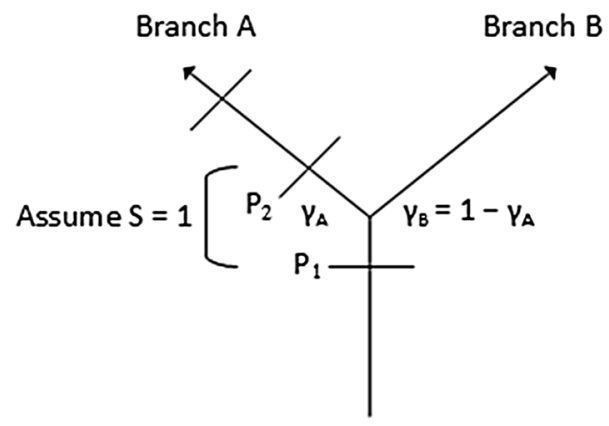

Fig. 3 Alternate receiver layout. Alternate receiver layout to estimate route selection probabilities $\gamma_{A}$ and $\gamma_{B}\left(\gamma_{A}+\gamma_{B}=1\right)$. This layout requires assumption of $100 \%$ survival between the lines before the branching point and first line after the branching point. $P$ denotes detection probability

Whether the receiver lines in a branch are modeled as separate lines (Fig. 2a) or as a dual array (Fig. 2b), it is necessary that detections on the two lines are independent events (assumption \#2). Fish that are detected on the first line of receivers in the branch must have the same probability of detection on the second line of receivers as fish that were present but not detected on the first line. This is a standard assumption of release-recapture models. Practically, this requires that at least one of the lines in a given leg be capable of detecting fish across the entire width of the river. Again, the risk of accident or equipment failure makes it safer to have all lines of receivers across the entire passage route.

The assumption of independence may be violated if the lines of receivers comprising a dual array are too close together. In such a case, a tag whose signal was missed on one line because of ambient noise or physical blockage of the signal or because the tag was between signal emissions when passing the detection array, will have a higher chance of non-detection on the second line of receivers. Physical separation of the two lines can help avoid this situation within the limitation of $100 \%$ survival between the two lines of receivers.

If the assumptions of independence and common survival to the first detection sites past the branching point are both met, then the user may use Program Branch to derive estimates of route selection probabilities $\left(\gamma_{\mathrm{A}}, \gamma_{\mathrm{B}}\right)$ and survival through the branch point. Assuming $S_{\mathrm{A}}=S_{\mathrm{B}}=S$, then $\gamma_{\mathrm{A}}=\frac{\phi_{\mathrm{A}}}{\phi_{\mathrm{A}}+\phi_{\mathrm{B}}}, \gamma_{\mathrm{B}}=1-\gamma_{\mathrm{A}}$, and $S=\phi_{\mathrm{A}}+\phi_{\mathrm{B}}$.

\section{Example: Shortnose suckers-Clear Lake Reservoir, California}

The shortnose sucker (Chasmistes brevirostris) is a listed endangered species under the Endangered Species Act (ESA). The survival and migration of a population of shortnose suckers in Clear Lake Reservoir, south of Klamath Falls, Oregon, was studied using radio tags and aerial reconnaissance. The adult shortnose suckers reside in the Clear Lake Reservoir in fall and winter months but migrate into Willow Creek during spring to spawn, returning to the reservoir in the summer. In autumn 2010, 53 shortnose suckers were captured, tagged, and released at Clear Lake Reservoir. Four surveys in 2011 and one in 2012 were used to model the survival and movement of shortnose suckers in the Clear Lake Reservoir and Willow Creek. For each aerial survey, tagged fish were classified as either detected in Clear Lake Reservoir, detected in Willow Creek or its tributaries or not detected. All tagging and telemetry surveys were performed by the US Bureau of Reclamation, Klamath Falls office.

A multistate model was created using Program Branch, allowing transitions between the reservoir and the creek (Fig. 4). Using the parameter nomenclature in Fig. 5, a product-multinomial likelihood was produced (Fig. 6) by the GUI-driven software to analyze the releaserecapture data. Transition probabilities were estimated that describe the joint probability of movement or lack of movement between locales and surviving between survey events (Fig. 7). Survival from release in October 2010 to the first survey (February 23, 2011) was 0.858 $\widehat{(\mathrm{SE}}=0.077)$. The aerial surveillance resulted in detection probability estimates that ranged from 0.559 to 1.0 over the course of the investigation (Fig. 7, Table 1). Transition probability estimates indicate that movement from the lake to Willow Creek was highest between the first and second surveys (i.e., February 23 to April 1, 2011), and adult shortnose suckers predominantly returned to the lake during the second and third surveys (i.e., between 1 April and May 24, 2011).

Overall survival was calculated as the sum of the transition probabilities for each possible route through the model. By bracketing the migration routes from release through the fourth survey event using the GUI, overall survival from October 2010 through August 2011 was estimated to be $0.594(\widehat{\mathrm{SE}}=0.083)$. Period-specific survival probabilities $\left(S_{i}\right)$ were calculated as the sum of the transition probabilities for each possible route to survey period $i$ divided by the sum of the transition probabilities for each possible route to survey period $i-1$. For example,

$$
S_{3}=\frac{\left[\phi_{\mathrm{LL} 2} \phi_{\mathrm{LL} 3}+\phi_{\mathrm{LR} 2} \phi_{\mathrm{RR} 3}+\phi_{\mathrm{LR} 2} \phi_{\mathrm{RL} 3}+\phi_{\mathrm{LL} 2} \phi_{\mathrm{LR} 3}\right]}{\left[\phi_{\mathrm{LL} 2}+\phi_{\mathrm{LR} 2}\right]},
$$

where $\phi_{h j i}=$ joint probability of transitioning from location $h$ (i.e., $\mathrm{L}$ denoting lake, $\mathrm{R}$ denoting river) and surviving between periods $i$ and $i+1$ to location $j$. 


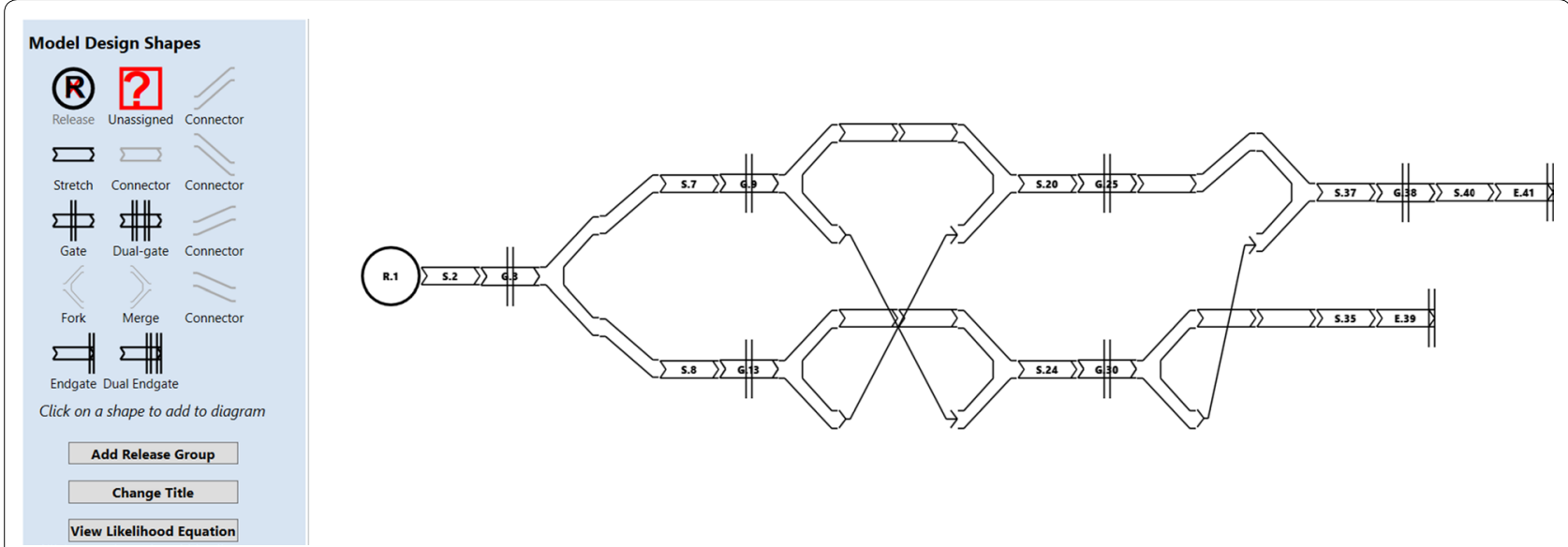

Fig. 4 Screen capture from Program Branch. Screen capture of graphic user interface (GUI) from Program Branch for the multistate model of movements of shortnose suckers, Clear Lake Reservoir, Oregon, 2010-2012. R.1 = release, S.x = "stretch" (e.g., reach or time period), G.x = "gate" (detection site), and $E . x=$ end gate

Fig. 5 Multistate model for shortnose sucker study. Multistate model for shortnose sucker study Clear Lake Reservoir, Oregon, 2010-2012, with
model parameters depicted. Parameters are: $\phi L L=$ probability of transitioning from the lake in period $i$ to the lake in period $i+1 ; \phi_{R R i}=$ probability
of transitioning from the river in period $i$ to the river in period $i+1 ; \phi L R i=$ probability of transitioning from lake in period $i$ to the river in period
$i+1$; etc. The $P$ denotes period-specific detection probabilities, and $\lambda_{L L}$, the joint probability of surviving in the lake within the last interval and
being detected

Period-specific survival estimates ranged from $\hat{S}_{3}=0.950$ $(\widehat{\mathrm{SE}}=0.049)$ to $\hat{S}_{2}=0.787(\widehat{\mathrm{SE}}=0.086)$. Survival was highest when the suckers were primarily in the Clear Lake Reservoir and lowest when in Willow Creek. These results suggest actions to protect this ESA-listed species may best be focused on improving survival in Willow Creek and its tributaries during the critical spawning period.

\section{Example: Chinook salmon smolts-San Joaquin River Delta}

The Sacramento-San Joaquin River Delta is located in the Central Valley of California (Fig. 8). The San Joaquin River flows northwest past Stockton, California, before joining the Sacramento River near Chipps Island on the way to San Francisco Bay. The Delta study area is bounded to the east and north by the San Joaquin
River. South of Stockton, near Mossdale Bridge, the Old River splits from the San Joaquin River and flows westward before turning north near the Central Valley Project and State Water Project, two water export facilities that draw water from the Delta. The Old River then rejoins the San Joaquin River just west of Mandeville Island. The Old River bounds the Delta study area on the southwest and west. The interior of the Delta is made up of the Middle River, which splits from the Old River, and various channels and cuts (Fig. 8). The upstream boundary of the study area is the release point at Durham Ferry, and the receiver array at Chipps Island marks the downstream limit of the study area. Between the release at Durham Ferry and the Chipps Island array, there are as many as 7 distinct routes for juvenile Chinook salmon to travel. 


$$
\begin{aligned}
& L\left(\phi_{i k}, \lambda_{i j}, P_{k}\right) \propto\left[\left[\phi_{L L 1} P_{1}\right]^{a_{L 1}} \times\left[\phi_{L L 1} \phi_{L L 2}\left(1-P_{1}\right) P_{2}\right]^{a_{L 2}} \times\left[\phi_{L L 1} \phi_{L R 2}\left(1-P_{1}\right) P_{2}\right]^{a_{R 2}}\right. \\
& \times\left[\left(\phi_{L L 1} \phi_{L L 2} \phi_{L L 3}+\phi_{L L 1} \phi_{L R 2} \phi_{R L 3}\right)\left(1-P_{1}\right)\left(1-P_{2}\right) P_{3}\right]^{a_{13}} \\
& \times\left[\left(\phi_{L L 1} \phi_{L R 2} \phi_{R R 3}+\phi_{L L 1} \phi_{L L 2} \phi_{L R 3}\right)\left(1-P_{1}\right)\left(1-P_{2}\right) P_{3}\right]^{a_{R 3}} \\
& \times\left[\phi_{L L 1}\left(\phi_{L L 2} \phi_{L L 3} \phi_{L L 4}+\phi_{L R 2} \phi_{R L 3} \phi_{L L 4}+\phi_{L L 2} \phi_{L R 3} \phi_{R L 4}+\phi_{L R 2} \phi_{R R 3} \phi_{R L 4}\right)\left(1-P_{1}\right)\left(1-P_{2}\right)\left(1-P_{3}\right) P_{4}\right]^{a_{L 4}} \\
& \left\{\times\left[\phi_{L L 1}\left(\phi_{L L 2} \phi_{L R 3} \phi_{R R 4}+\phi_{L R 2} \phi_{R R 3} \phi_{R R 4}\right)\left(1-P_{1}\right)\left(1-P_{2}\right)\left(1-P_{3}\right) P_{4}\right]^{a_{R 4}}\right. \\
& \times\left[\phi_{L L 1}\left(\phi_{L L 2} \phi_{L L 3} \phi_{L L 4}+\phi_{L R 2} \phi_{R L 3} \phi_{L L 4}+\phi_{L L 2} \phi_{L R 3} \phi_{R L 4}+\phi_{L R 2} \phi_{R R 3} \phi_{R L 4}\right) \lambda_{L L}\left(1-P_{1}\right)\left(1-P_{2}\right)\left(1-P_{3}\right)\left(1-P_{4}\right)\right]^{a_{L S}} \\
& {\left[\begin{array}{l}
1-\phi_{L L 1}+\phi_{L L 1}\left(1-P_{1}\right)\left(1-\phi_{L L 2}-\phi_{L R 2}+\phi_{L L 2}\left(1-P_{2}\right)\left(1-\phi_{L L 3}-\phi_{L R 3}+\phi_{L L 3}\left(1-P_{3}\right)\left(1-\phi_{L L 4}\right.\right.\right. \\
\left.\left.+\phi_{L L 4}\left(1-P_{4}\right)\left(1-\lambda_{L L}\right)\right)+\phi_{L R 3}\left(1-P_{3}\right)\left(1-\phi_{R L 4}-\phi_{R R 4}+\phi_{R L 4}\left(1-P_{4}\right)\left(1-\lambda_{L L}\right)+\phi_{R R 4}\left(1-P_{4}\right)\right)\right) \\
+\phi_{L R 2}\left(1-P_{2}\right)\left(\phi_{R L 3}\left(1-P_{3}\right)\left(1-\phi_{L L 4}+\phi_{L L 4}\left(1-P_{4}\right)\left(1-\lambda_{L L}\right)\right)+\phi_{R R 3}\left(1-P_{3}\right)\left(1-\phi_{R L 4}-\phi_{R R 4}\right.\right. \\
\left.\left.\left.+\phi_{R L 4}\left(1-P_{4}\right)\left(1-\lambda_{L L}\right)+\phi_{R R 4}\left(1-P_{4}\right)\right)\right)\right)
\end{array}\right]^{\alpha_{0}}} \\
& \times\left[\left[\phi_{L L 2} P_{2}\right]^{a_{22 \mid 121}} \times\left[\phi_{L R 2} P_{2}\right]^{a_{R 2 \mid 12}} \times\left[\left(\phi_{L L 2} \phi_{L L 3}+\phi_{L R 2} \phi_{R L 3}\right)\left(1-P_{2}\right) P_{3}\right]^{a_{33 \mid 121}}\right. \\
& \times\left[\left(\phi_{L R 2} \phi_{R R 3}+\phi_{L L 2} \phi_{L R 3}\right)\left(1-P_{2}\right) P_{3}\right]^{a_{R 3 Z L 1}} \\
& \times\left[\left(\phi_{L L 2} \phi_{L L 3} \phi_{L L 4}+\phi_{L R 2} \phi_{R L 3} \phi_{L L 4}+\phi_{L L 2} \phi_{L R 3} \phi_{R L 4}+\phi_{L R 2} \phi_{R R 3} \phi_{R L 4}\right)\left(1-P_{2}\right)\left(1-P_{3}\right) P_{4}\right]^{a_{I 4 L 1}} \\
& \times\left[\left(\phi_{L L 2} \phi_{L R 3} \phi_{R R 4}+\phi_{L R 2} \phi_{R R 3} \phi_{R R 4}\right)\left(1-P_{2}\right)\left(1-P_{3}\right) P_{4}\right]^{a_{R 4 L 1}} \\
& \left\{\times\left[\left(\phi_{L L 2} \phi_{L L 3} \phi_{L L 4}+\phi_{L R 2} \phi_{R L 3} \phi_{L L 4}+\phi_{L L 2} \phi_{L R 3} \phi_{R L 4}+\phi_{L R 2} \phi_{R R 3} \phi_{R L 4}\right) \lambda_{L L}\left(1-P_{2}\right)\left(1-P_{3}\right)\left(1-P_{4}\right)\right]^{a_{S S L L 1}}\right. \\
& \times\left[\begin{array}{l}
1-\phi_{L L 2}-\phi_{L R 2}+\phi_{L L 2}\left(1-P_{2}\right)\left(1-\phi_{L L 3}-\phi_{L R 3}+\phi_{L L 3}\left(1-P_{3}\right)\left(1-\phi_{L L 4}+\phi_{L L 4}\left(1-P_{4}\right)\left(1-\lambda_{L L}\right)\right)\right)^{a_{\text {olL1 }}} \\
\left.+\phi_{L R 3}\left(1-P_{3}\right)\left(1-\phi_{R L 4}-\phi_{R R 4}+\phi_{R L 4}\left(1-P_{4}\right)\left(1-\lambda_{L L}\right)+\phi_{R R 4}\left(1-P_{4}\right)\right)\right) \\
+\phi_{L R 2}\left(1-P_{2}\right)\left(\phi_{R L 3}\left(1-P_{3}\right)\left(1-\phi_{L L 4}+\phi_{L L 4}\left(1-P_{4}\right)\left(1-\lambda_{L L}\right)\right)\right. \\
\left.+\phi_{R R 3}\left(1-P_{3}\right)\left(1-\phi_{R L 4}-\phi_{R R 4}+\phi_{R L 4}\left(1-P_{4}\right)\left(1-\lambda_{L L}\right)+\phi_{R R 4}\left(1-P_{4}\right)\right)\right)
\end{array}\right]
\end{aligned}
$$

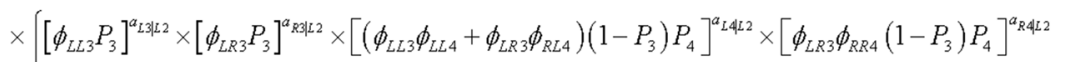

$$
\begin{aligned}
& \times\left[\left(\phi_{L L 3} \phi_{L L 4}+\phi_{L R 3} \phi_{R L 4}\right) \lambda_{L L}\left(1-P_{3}\right)\left(1-P_{4}\right)\right]^{a_{L S 1 L 2}} \\
& {\left[\times\left[\begin{array}{l}
1-\phi_{L L 3}-\phi_{L R 3}+\phi_{L L 3}\left(1-P_{3}\right)\left(1-\phi_{L L 4}+\phi_{L L 4}\left(1-P_{4}\right)\left(1-\lambda_{L L}\right)\right)+\phi_{L R 3}\left(1-P_{3}\right)\left(1-\phi_{R L 4}-\phi_{R R 4}\right. \\
\left.+\phi_{R L 4}\left(1-P_{4}\right)\left(1-\lambda_{L L 2}\right)+\phi_{R R 4}\left(1-P_{4}\right)\right)
\end{array}\right]\right.} \\
& \times\left[\left[\phi_{R L 3} P_{3}\right]^{a_{33 P 22}} \times\left[\phi_{R R 3} P_{3}\right]^{a_{R 3 P 22}} \times\left[\left(\phi_{R L 3} \phi_{L L 4}+\phi_{R R 3} \phi_{R L 4}\right)\left(1-P_{3}\right) P_{4}\right]^{a_{L 4 Q 22}} \times\left[\phi_{R R 3} \phi_{R R 4}\left(1-P_{3}\right) P_{4}\right]^{a_{R A Q R 2}}\right. \\
& \times\left[\left(\phi_{R L 3} \phi_{L L 4}+\phi_{R R 3} \phi_{R L 4}\right) \lambda_{L L}\left(1-P_{3}\right)\left(1-P_{4}\right)\right]^{a_{L S P R 2}} \\
& \times\left[\begin{array}{l}
\phi_{R L 3}\left(1-P_{3}\right)\left(1-\phi_{L L 4}+\phi_{L L 4}\left(1-P_{4}\right)\left(1-\lambda_{L L}\right)\right)+\phi_{R R 3}\left(1-P_{3}\right)\left(1-\phi_{R L 4}-\phi_{R R 4}+\phi_{R R 4}\left(1-P_{4}\right)\right. \\
\left.+\phi_{L L 4}\left(1-P_{4}\right)\left(1-\lambda_{L L}\right)\right)
\end{array}\right] \\
& \times\left\{\left[\phi_{L L 4} P_{4}\right]^{a_{L 4 L 23}} \times\left[\phi_{L L 4} \lambda_{L L}\left(1-P_{4}\right)\right]^{a_{L S L 3}} \times\left[1-\phi_{L L 4}+\phi_{L L 4}\left(1-P_{4}\right)\left(1-\lambda_{L L}\right)\right]^{a_{\| 123}}\right\}
\end{aligned}
$$

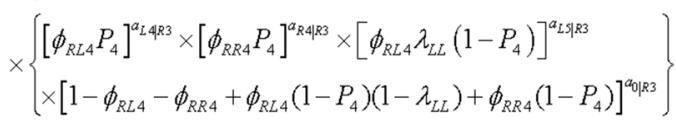

$$
\begin{aligned}
& \times\left\{\left[\lambda_{L L}\right]^{a_{L S L L 4}} \times\left[1-\lambda_{L L}\right]^{a_{0 L L 4}}\right\}
\end{aligned}
$$

Fig. 6 Product-multinomial likelihood equation. Product-multinomial likelihood equation used to estimate parameters for shortnose sucker, Clear Lake Reservoir, Oregon, 2010-2012. Parameter names follow terminology in Fig. 5. Statistics $a_{i / j}$ are the number of tags detected at site $j$, given their detection at site $i$. The $\phi_{h j i}$ denote the joint probability of transitioning from location $h$ to location $j$ and surviving between periods $i$ and $i+1 ; P_{i \prime}$ the detection probability in period $i$; and $\lambda_{L L}$, the joint probability of surviving the last period in the lake and being detected

A total of 1895 acoustic-tagged juvenile Chinook salmon were released in spring 2011 for the purpose of estimating overall survival through the Delta as well as route-specific survival and movement probabilities. Information from this and other investigations is being used to improve the migration success of juvenile salmonids through the Sacramento-San Joaquin River Delta [20]. This study was conducted under the aegis of the San Joaquin River Group Authority under the Vernalis Adaptive Management Plan. 


Fig. 7 Multistate model with parameter estimates. Fitted multistate model with parameter estimates for shortnose sucker, Clear Lake Reservoir,
Oregon, 2010-2012. The joint transition and survival parameters (i.e., $\phi$ ) are reported along with period-specific detection probabilities (P). Standard
errors for the parameter estimates can be found in Table 1

Table 1 Estimates of transition parameters

\begin{tabular}{lll}
\hline Parameter & Estimate & $\widehat{\text { SE }}$ \\
\hline$\phi_{\mathrm{LL} 1}$ & 0.858 & 0.077 \\
$\phi\llcorner\mathrm{L} 2$ & 0.279 & 0.093 \\
$\phi_{\mathrm{LR} 2}$ & 0.508 & 0.100 \\
$\phi_{\mathrm{LL} 3}$ & 0.656 & 0.166 \\
$\phi_{\mathrm{LR} 3}$ & 0.203 & 0.129 \\
$\phi_{\mathrm{RL} 3}$ & 0.722 & 0.100 \\
$\phi_{\mathrm{RR} 3}$ & 0.278 & 0.100 \\
$\phi_{\mathrm{LL4}}$ & 0.895 & 0.090 \\
$\phi_{\mathrm{RL} 4}$ & 0.237 & 0.148 \\
$\phi_{\mathrm{RR} 4}$ & 0.778 & 0.202 \\
$\lambda_{1}$ & 0.571 & 0.108 \\
$P_{1}$ & 0.571 & \\
$P_{2}$ & 0.559 & \\
$P_{3}$ & 1.0 & \\
$P_{4}$ & 0.857 &
\end{tabular}

Estimates of transition parameters and associated standard errors (SE) for shortnose sucker movements in Clear Lake Reservoir, Oregon, 2010-2012. Parameter names follow terminology in Fig. 1, where $\phi$ denotes joint probabilities of survival and movement; $P$, detection probabilities; and $\lambda$, the joint probability of survival and detection in the terminal interval of the study

A multistate model for the San Joaquin River study was generated using the GUI capabilities of Program Branch (Fig. 9). Because of the complexity of this model, the likelihood is too long to display; it is roughly six times larger than the model for the shortnose suckers displayed in Fig. 6. Survival of juvenile Chinook salmon through the Delta in 2011 was low across all routes, although survival was significantly higher $(P<0.0001)$ among Chinook salmon migrating through Old River than among those migrating through San Joaquin River. Overall survival for juvenile Chinook salmon through the San Joaquin-Sacramento Delta in 2011 (from Durham Ferry to Chipps
Island) was estimated at $0.018(\widehat{\mathrm{SE}}=0.003)$, which is very low. The joint probability of migration and survival from Durham Ferry to Chipps Island was also estimated for two distinct routes: through the San Joaquin River $(\hat{\Phi}=0.0039, \widehat{\mathrm{SE}}=0.0014)$ and through Old River $(\hat{\Phi}=0.0136, \widehat{\mathrm{SE}}=0.0027)$.

The survival probabilities estimated for the juvenile Chinook salmon in the San Joaquin River are very low, especially when considering the distances travelled. In this study, the hatchery Chinook salmon experienced a survival probability of 0.018 over approximately $50 \mathrm{~km}$. For context, yearling Chinook salmon migrating $500 \mathrm{~km}$ through the Snake/Columbia River in the Pacific Northwest, passing through eight hydroelectric projects, have an average survival probability of approximately 0.50 [30]. Numerous mitigation actions including habitat restoration and predator control will be necessary in the San Joaquin River before passage survival reaches acceptable levels.

\section{Example: Adult steelhead-Snake River}

Steelhead (anadromous Rainbow Trout Oncorhynchus mykiss) in the Columbia River Basin are listed as threatened under the Endangered Species Act of 1973, and their juvenile seaward migrations have been studied for years using passive integrated transponder (PIT) tags [21, 31-33]. Recently focus has shifted to the adult spawning migration. Adult steelhead are known to enter freshwater as early as a year before spawning, and to use a wide range of habitats before returning to their natal stream to spawn. Before river impoundment began, this behavior may have supported individual survival and population persistence by allowing steelhead to find and use temperature refugia or other habitat suitable for spawning [34]. However, the current river system includes large hydroelectric dams, and fish that stray or overshoot their natal 


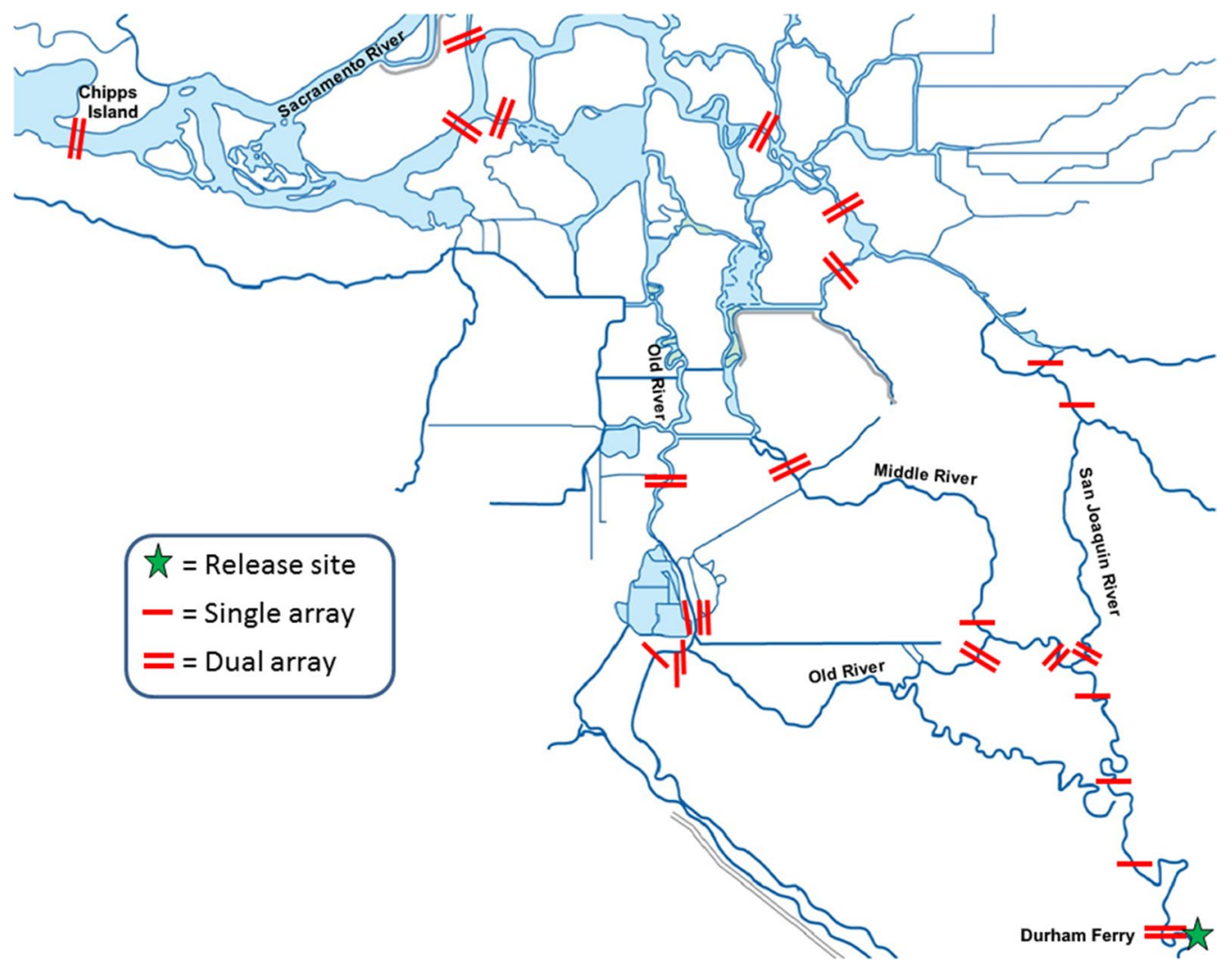

Fig. 8 Map of hydrophone detection arrays in acoustic tag study. Map of hydrophone detection arrays used in the 2011 acoustic tag study of juvenile Chinook salmon smolts in the Sacramento-San Joaquin River Delta, California

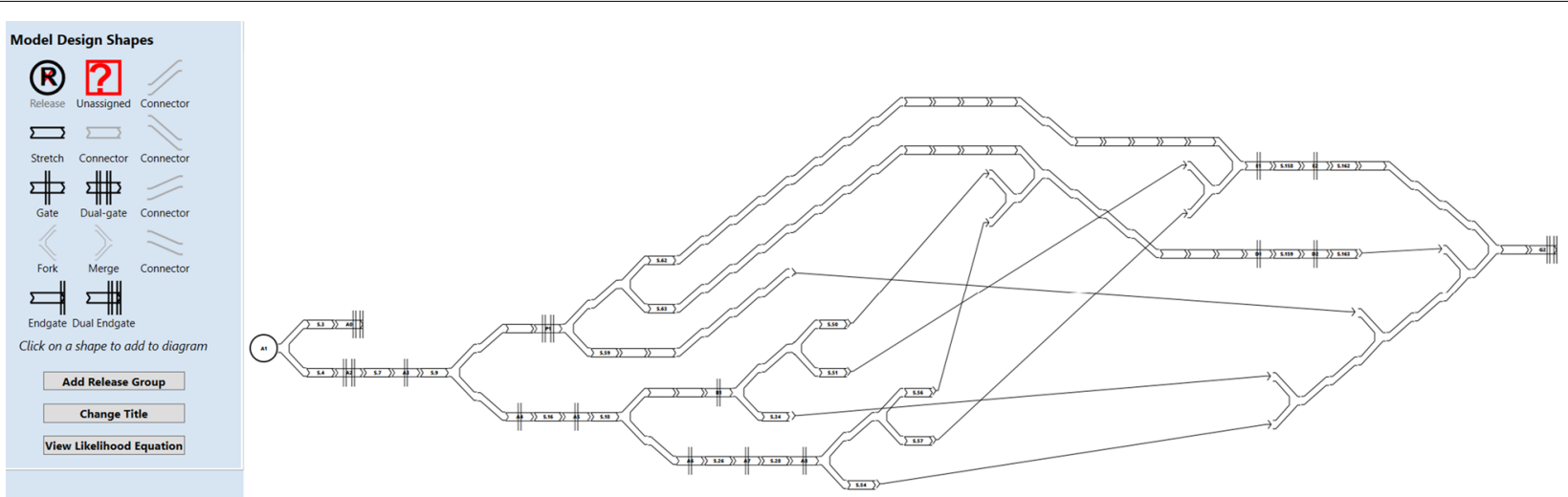

Fig. 9 Screen capture from Program Branch. Graphic user interface (GUI) from Program Branch for the multistate model of movements of Chinook salmon smolts through the Sacramento-San Joaquin River Delta, California, 2011. Tag release location denoted (R) on the left with movements proceeding to the right

streams by ascending these dams before spawning may not be able later to return and successfully spawn [35]. Thus, there is a need to know spawning success rates and whether hydroelectric dams may impede steelhead who overshoot their natal stream from successfully spawning.
Populations of naturally spawned steelhead are augmented with large-scale hatchery programs in the Columbia River Basin. Hatchery-raised juvenile steelhead are typically released in a variety of tributaries to the Columbia and Snake rivers, and are expected to return to 
those release sites as adults. Some of the juvenile hatchery steelhead are tagged with PIT tags before release, which allows observations on behavior and survival as they return as adults, using detections from fish ladders at dams, in-stream antenna arrays in tributaries, and captures at hatcheries and weirs.

PIT-tagged adult steelhead that had previously been reared at the Lyons Ferry Hatchery on the Snake River in southeastern Washington State and released as juveniles in the Walla Walla River, a tributary to the Columbia River, were detected at Bonneville Dam between June 1, 2009, and May 31, 2010, and monitored as they continued migrating upriver (Fig. 10). A total of 416 PIT-tagged adult steelhead were detected at Bonneville Dam; 69 of these fish were eventually observed in the Walla Walla River, either at an in-stream PIT-tagged antenna array in the lower Walla Walla River at Oasis Road Bridge or at sites farther upstream in the Walla Walla. Some of these 416 steelhead were observed passing either Lower Granite Dam on the Snake River or Priest Rapids Dam on the middle Columbia River before returning downstream to the Walla Walla River; others that were detected at Lower Granite or Priest Rapids continued upstream and did not return to the Walla Walla River.
A multistate model for the Walla Walla origin steelhead migration was generated using Program Branch (Fig. 11). The model allows transitions to the Walla Walla River either directly from the closest downstream dam (McNary Dam, Fig. 10) or from fallback behavior from upstream dams in the upper Columbia River (i.e., Priest Rapids) or the Snake River (i.e., Lower Granite Dam). The detection probability at the lower Walla Walla River in-stream array was estimated to be 0.454 (SE 0.106), based on detections and recaptures of PITtagged fish from upstream in the Walla Walla River. The probability of moving directly from McNary Dam to the Walla Walla River (i.e., without ascending either Lower Granite or Priest Rapids dams) was estimated at 0.354 $(\widehat{\mathrm{SE}}=0.080)$. The estimated probability of moving from McNary to Lower Granite was $0.342(\widehat{\mathrm{SE}}=0.026)$, and of moving from McNary to Priest Rapids was 0.037 (SE $=0.014$ ). The probability of returning to the Walla Walla River was estimated to be $0.083(\widehat{\mathrm{SE}}=0.040)$ for fish that ascended Lower Granite, and $0.202(\widehat{\mathrm{SE}}=0.194)$ for fish that ascended Priest Rapids. The overall probability of an adult Walla Walla origin steelhead detected at Bonneville Dam successfully returning to the Walla Walla River to spawn was estimated at $0.301(\widehat{\mathrm{SE}}=0.068)$.

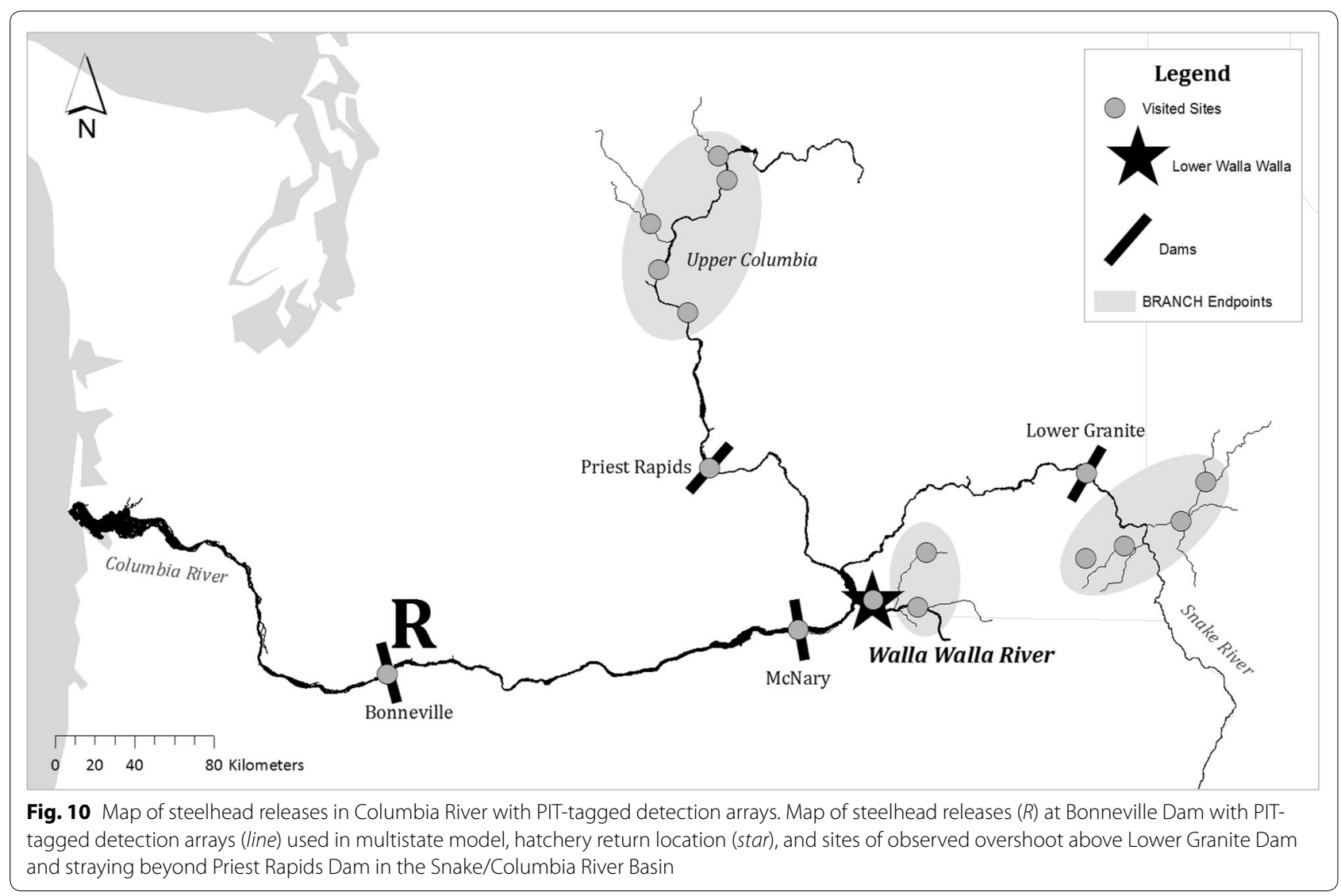




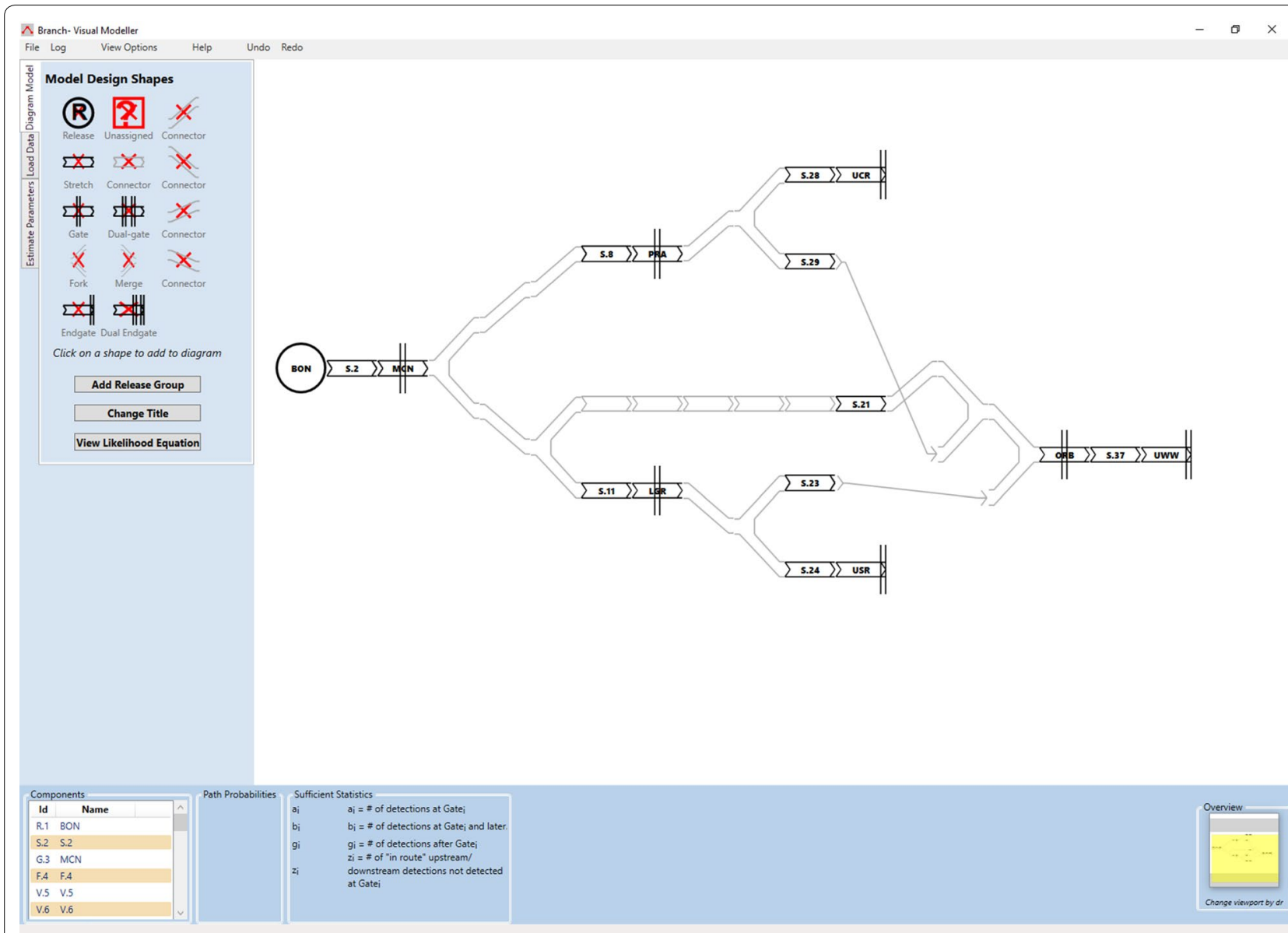

Fig. 11 Screen capture from Program Branch. Screen capture of graphic user interface (GUI) from Program Branch for a multistate model of movements of adult steelhead released at Bonneville Dam as they migrate to their spawning grounds in the Walla Walla River or stray into the Mid-

Columbia River or overshoot into the Snake River. The model allows for fish that overshoot or stray to eventually return to their natal river to spawn.

The tag release $(R)$ starts on the left with movements toward the right-hand side of the model

These hatchery steelhead, reared in Lyons Ferry Hatchery on the Snake River but released in the Walla Walla River, were more likely as adults to overshoot in the Snake River than into the upper Columbia River. Unfortunately, coupled with higher overshoot rates into the Snake River was a lower rate of successful fallback. These factors contributed to a rather low spawning success rate of only 0.301 . This example illustrates the importance of examining hatchery rearing and release practices in order to reduce overshooting behavior in migratory adult steelhead and increase spawning success.

\section{Discussion}

Program Branch was developed to provide a flexible environment to accommodate varying research objectives and diverse migration routes and detection configurations. The multistate models developed by Program
Branch can be used to characterize the movement behavior of fish at large spatial scales such as river basins or tributary systems as well as small-scale movements of fish through hydroelectric projects or water diversion facilities as described in the San Joaquin River Delta example. In the Columbia/Snake River Basin, where this software was developed, over 200 adult and juvenile PIT-tag detection arrays located in over three states have been established to monitor juvenile and adult migration success. In addition to the PIT-tag capabilities, numerous acoustic- and radio-tag studies are conducted with a diverse range of objectives and wide array of detection configurations. Multistate models will be the primary means of analysis for most of these studies, and Program Branch was designed to facilitate these analyses.

The listing of 13 salmonid populations as threatened or endangered in the Columbia River Basin under the 
Endangered Species Act of 1973 has driven the need for vast amounts of information, often outpacing analytical capabilities. Too often in the past, tagging studies have been implemented by investigators with the hope the resulting data will be useful-only to discover afterward that key elements of the release and redetection schemes were inadequate to yield estimable results. Rapid, easy, and reliable model development can help ensure design configurations will provide the desired survival and movement parameters before a tagging study begins. For instance, after the GUI in Program Branch is used to create a tagging model, the software assesses estimability by examining the separability of parameters and whether there are an adequate number of minimum sufficient statistics. If found deficient, the investigator is alerted the release-recapture design needs to be restructured if the estimation goals are to be met. Multistate models that previously took days or weeks to construct and do QA can now be developed in minutes or hours with Program Branch. This ease in model construction encourages investigators to be more proactive in the design evaluation and the examination of alternative study designs. The graphically driven interface also expands the opportunities for model development and exploration by a wider range of users. The hope is more informed analyses will be performed and fewer studies conducted with design flaws. This should benefit resource decisions and improve the use of financial resources directed at recovery programs.

More development is planned on Program Branch to these ends. Currently, Program Branch can be used to model multiple tag releases. Staggered releases over time within the same multistate framework are permitted, along with independent releases that might share only part of the multistate framework of another release. In the latter case, the GUI would depict the release-recapture processes as a series of stacked, non-connected pathways. Simple three-dimensional multistate models can be represented using stacked diagrams in the GUI. Examples include migration over time and space, and differentiated by sex or age classes of the animals. Buchanan et al. [21] used a three-dimensional multistate model to describe the downriver migration of juvenile steelhead over multiple age classes that included possible residualization as they migrated to the ocean. The current version of Program Branch can be used to depict the fully parameterized model of Buchanan et al. [21] but not special cases where parameter values are shared across release groups. Refinements to Program Branch will permit setting migration and/or detection parameters common across migrant groups.

A critical concern in the use of complex multistate models is sample size. There is the natural concern over the precision of directly estimated as well as derived parameter values. A less obvious but nevertheless important concern is sparse data that can lead to the inability to calculate values for otherwise estimable parameters or functions of parameters. A multiplicity of potential pathways coupled with small sample size or infrequently used migration routes can make maximum likelihood estimation difficult or impossible. Program Branch will alert users to this potential problem when calculating minimum sufficient statistics after the fact. A Monte Carlo simulation capability will soon be added to the program which will not only provide estimates of anticipated sampling precision but also rates of model failure due to sparse data. This is one more step in helping assure costly and important tagging studies are designed and analyzed to produce timely information for resource managers.

\section{Conclusions}

Release-recapture studies conducted in time and space can be represented schematically and translated into a quantitative framework using adjacency matrices. Program Branch uses this quantitative approach to automatically derive likelihood models for release-recapture studies based on a user-driven graphical interface (GUI). This GUI approach greatly simplifies the modeling of complex studies of fish migration and survival. Models that previously took days or weeks to construct can now be developed in minutes or hours. This GUI approach to model construction should also expand the pool of practitioners capable of analyzing complex multistate investigations. The GUI of Program Branch also allows investigators to generate salient summaries of releaserecapture studies automatically. This convenient software approach to multistate modeling should improve both the design and analysis of release-recapture studies, thereby improving the demographic information available to resource managers.

\section{Abbreviations \\ GUI: graphic user interface; ID: identification; PIT: passive integrated tran- sponder; QA: quality assurance; QA/QC: quality assurance/quality control; SE: standard error.}

\section{Authors' contributions}

ACP developed the initial software capabilities. TL developed Program Branch under the supervision of JRS. JRS, ACP, and RAB wrote the paper and performed the data analyses. All authors read and approved the final manuscript.

\section{Author details}

${ }^{1}$ Quantitative Ecology and Resource Management, University of Washington, 1325 Fourth Avenue, Suite 1515, Seattle, WA 98101-2540, USA. ${ }^{2}$ Present Address: US Geological Survey, Western Fisheries Research Center, Columbia River Research Laboratory, 5501-A Cook-Underwood Road, Cook, WA 98605, USA. ${ }^{3}$ School of Aquatic and Fishery Sciences, University of Washington, 1325 Fourth Avenue, Suite 1515, Seattle, WA 98101-2540, USA. 


\section{Acknowledgements}

Software research and development was funded by the Bonneville Power Administration, Project 1989-107-00. The Clear Lake Reservoir adult shortnose sucker radio-tag data were provided by the US Bureau of Reclamation. The San Joaquin Chinook salmon data were provided by the California Department of Water Resources, and the Columbia/Snake River adult steelhead data were obtained from the PIT Tag Information System (PTAGIS) managed by the Pacific States Marine Fisheries Commission.

\section{Competing interests}

The authors declare that they have no completing interests.

\section{Availability of data and materials}

The freeware Program Branch 1.0 can be obtained from the University of Washington at http://www.cbr.washington.edu/analysis/apps/branch. The PIT-tagged adult steelhead data can be obtained from the PIT Tag Information System (PTAGIS) at http://www.ptagis.org/home.

\section{Ethics approval}

No animals were handled or harmed in developing Program Branch. Authors used archived data from federally conducted tagging studies in developing the illustrations.

Received: 18 July 2016 Accepted: 14 November 2016

Published online: 03 December 2016

\section{References}

1. Cormack RM. Estimates of survival from the sighting of marked animals. Biometrika. 1964;51:429-38.

2. Brownie C, Anderson DR, Burnham KP, Robson DS. Statistical inference from band recovery data-a handbook. US Fish and Wildlife Service, Patuxent Wildlife Research Center, resource publication. 1985; 156.

3. Prentice EE, Flagg TA. PIT tag monitoring for hydroelectric dams and fish hatcheries. Am Fish Soc Symp. 1990;7:323-34.

4. Prentice EF, Flagg TA, McCutcheon CS. Feasibility of using implantable passive integrated transponder (PIT) tags in salmonids. Am Fish Soc Symp. 1990;7:317-22.

5. Peters $L$, Reinhardt U, Pegg MA. Factors influencing radio wave transmis sion and reception: use of radiotelemetry in large river systems. N Am J Fish Manag. 2008;28:301-7.

6. Eiler JH. Tracking aquatic animals with radio telemetry. In: Adams NS, Beeman JW, Eiler JH, editors. Telemetry techniques: a user guide for fisheries research. Bethesda, MD: American Fisheries Society; 2012. p. 163-204.

7. Stuehrenberg L, Giorgi A, Bartlett C. Pulse-coded radio tags for fish identifcation. Am Fish Soc Symp. 1990;7:370-4.

8. McMichael GA, Eppard MB, Carlson TJ, Carter JA, Ebberts BD, Brown RS, Weiland M, Ploskey GR, Harnish RA, Deng ZD. The juvenile salmon acoustic telemetry system: a new tool. Fisheries. 2010;35:9-22.

9. Espinoza M, Farrugia TJ, Webber DM, Smith F, Lowe CG. Testing a new acoustic telemetry technique to quantify long-term, fine-scale movements of aquatic animals. Fish Res. 2011;108:364-71.

10. Block BA, Dewar H, Farwell C, Prince ED. A new satellite technology for tracking the movements of Atlantic bluefin tguna. Proc Natl Acad Sci USA. 1998;95:9384-9.

11. Jaine FRA, Rohner CA, Weeks SJ, Jaine LIE, Rohner MB, Couturier KA, Richardson AJ, Jaine AJ, Rohner AJ, Couturier AJ, et al. Movements and habitat use of reef manta rays off eastern Australia: offshore excursions, deep diving and eddy affinity revealed by satellite telemetry. Mar Ecol Prog Ser. 2014;510:73-86.

12. Hestbeck JB, Nichols JD, Malecki RA. Estimates of movement and site fidelity using mark-resight data of wintering Canada geese. Ecology. 1991;72:523-33.

13. Lebreton JD, Hines JE, Pradel R, Nichols JD, Spendelow JA. Estimation by capture-recapture of recruitment and dispersal over several sites. Oikos. 2003;101:253-64
14. Doherty JPF, Schreiber EA, Nichols JD, Hines JE, Link WA, Schenk GA, Schreiber RW. Testing life history predictions in a long-lived seabird: a population matrix approach with improved parameter estimation. Oikos. 2004;105:606-18.

15. Aars J, Ims RA. The effect of habitat corridors on rates of transfer and interbreeding between vole demes. Ecology. 1999;80:1648-55.

16. Pyne Ml, Byrne KM, Holfelder KA, McManus L, Buhnerkempe M, Burch N, Childers E, Hamilton S, Schroeder G, Doherty PF. Survival and breeding transitions for a reintroduced bison population: a multistate approach. J Wildl Manage. 2010;74:1463-71.

17. Buchanan RA, Skalski JR. Using multistate mark-recapture methods to model adult salmonid migration in an industrialized river. Ecol Model. 2010;221:582-9.

18. Buchanan RA, Skalski JR, Smith SG. Estimating the effects of smolt transportation from different vantage points and management perspectives. N Am J Fish Manag. 2006;26:460-72.

19. Perry RW, Skalski JR, Brandes PL, Sandstrom PT, Klimley AP, Ammann A, MacFarlane B. Estimating survival and migration route probabilities of juvenile Chinook salmon in the Sacramento-San Joaquin River Delta. N Am J Fish Manag. 2010:30:142-56.

20. Buchanan RA, Skalski JR, Brandes P, Fuller A. Route use and survival of juvenile Chinook salmon through the San Joaquin Delta. N Am J Fish Manag. 2013;33:216-29.

21. Buchanan RA, Skalski JR, Mackey G, Snow C, Murdoch AR. Estimating cohort survival through tributaries for salmonid populations with variable ages at migration. N Am J Fish Manag. 2015;35:958-73.

22. Choquet R, Choquet R, Reboulet AM, Pradel R, Gimenez O, Lebreton JD. M-SURGE: new software specifically designed for multistate capturerecapture models. Anim Biodivers Conserv. 2004:27:207-15.

23. White GC, Burnham KP. Program MARK: survival estimation from populations of marked animals. Bird Study. 1999:46:120-38.

24. White GC, Kendall WL, Barker RJ. Multistate survival models and their extensions in Program MARK. J Wild Manag. 2006:70:1521-9.

25. King R, Brooks SP. Closed-form likelihoods for Arnason-Schwarz models. Biometrika. 2003:90:435-44.

26. Fujiwara $\mathrm{M}$, Caswell $\mathrm{H}$. Estimating population projection matrices from multi-stage mark-recapture data. Ecology. 2002;83:3257-65.

27. Kendall MG, Stuart A. The advanced theory of statistics: inference and relationship. New York: Macmillan; 1979.

28. Bang-Jensen J, Gutin G. Digraphs: theory, algorithms and applications. 2nd ed. London: Springer; 2010

29. Seber GAF. The estimation of animal abundance and related parameters. New York: Macmillan; 1982.

30. Faulkner JR, Morris MS, Widener DL, Bentley PJ, Marsh TM, Smith SG, Zabe RW: Survival estimate for the passage of spring-migrating juvenile salmonids through Snake and Columbia river dams and reservoirs, 2015. Report to the Bonneville Power Administration, BPA Project \# 1993-029-00; 2016.

31. Skalski JR, Smith SG, Iwamoto RN, Williams JG, Hoffmann A. Use of passive integrated transponder tags to estimate survival of migrating juvenile salmonids in the Snake and Columbia Rivers. Can J Fish Aquat Sci. 1998:55:1484-93.

32. Muir WD, Smith SG, Williams JG, Hockersmith EE. Survival estimates for migrant yearling Chinook salmon and steelhead tagged with passive integrated transponders in the lower Snake and lower Columbia rivers. N Am J Fish Manag. 2001:21:269-82.

33. Buchanan RA, Skalski JR. A migratory life-cycle release-recapture model for salmonid PIT-tag investigations. J Agric Biol Environ Stat. 2007; 12:325-45.

34. Quinn TP. The behavior and ecology of Pacific salmon and trout. Seattle: American Fisheries Society in association with University of Washington Press; 2005.

35. Keefer ML, Caudill CC, Peery CA, Boggs CT. Non-direct homing behaviours by adult Chinook salmon in a large, multi-stock river system. J Fish Biol. 2008:72:27-44 